\title{
ESTADO DA ARTE: UTILIZAÇÃO DO MÉTODO INVESTIGATIVO NA DISCIPLINA DE FÍSICA NO PERÍODO DE 2013-2018
}

\author{
STATE OF ART: USE OF RESEARCH METHOD IN PHYSICAL DISCIPLINE \\ 2013-2018
}

DOI: http://dx.doi.org/10.23926/RPD.2526-2149.2020.v5.n1.p344-359.id622

\section{Jéferson Pereira da \\ Silva \\ Mestre em Ensino \\ (IFMT/UNIC) \\ jefersonjuniorpereira@hotma \\ $\underline{\text { il.com }}$}

\section{Thiago Andrade de \\ Toledo}

Doutor em Física (UFSCar)

Professor no Instituto

Federal de Mato Grosso,

Centro de Referência de

Jaciara (IFM-CRJac).

thiagotoledo21@gmail.com

\section{Leandro Carbo}

Doutor em Química (IQ-

UNESP)

Professor no Instituto

Federal de Mato Grosso,

Centro de Referência de

Jaciara (IFM-CRJac).

leandro.carbo@svc.ifmt.edu. $\underline{b r}$
Resumo: Atualmente, existe considerável aumento de pesquisas do cunho metodológico "estado do conhecimento" ou "estado da arte", a fim de pesquisar e divulgar como tem se dado os estudos recentes. Assim, diversos são os trabalhos que permeiam as estratégias para o aprimoramento do ensino e aprendizagem de Ciências (física, química, matemática e biologia). O presente artigo visou averiguar e descrever como tem se dado a utilização do método investigativo, no ensino de física e os temas já abordados, haja vista que se trata de um método primordial para a promoção da alfabetização científica. Mediado pela busca com três descritores, selecionando trabalhos publicados completos, dispondo de filtros na base de dados da Google Acadêmico e do SciELO, com recorte temporal dos últimos cinco anos (2013-1018). Desta forma, foram analisados 10 artigos, 02 dissertações e 01 tese que retrata o ensino investigativo. Logo, evidenciando baixo quantitativo de pesquisas que permeiam esta área do conhecimento.

Palavras-chave: Estado da Arte; Ensino de Física; Investigação no Ensino de Física; EnCI.

\begin{abstract}
Currently, there is a considerable increase in research of the methodological nature "state of knowledge" or "state of the art", in order to research and disseminate how recent studies have been doing. Thus, there are several works that permeate the strategies for improving the teaching and learning of Sciences (physics, chemistry, mathematics and biology). This article aimed to investigate and describe how the investigative method has been used in teaching physics and the topics already addressed, given that it is a primary method for the promotion of scientific literacy. Mediated by searching with three descriptors, selecting complete published works using filters in the Google Scholar and SciELO database, with a time frame of the last five years (2013-1018). Thus, 10 articles, 02 dissertations and 01 thesis that permeates investigative teaching were analyzed. Therefore, showing a low amount of research that permeates this area of knowledge.
\end{abstract}

Keywords: State of the Art; Physics teaching; Physics teaching research; EnCI. 


\section{INTRODUÇÃO}

Estudos recentes na área do ensino de física apontam a dificuldade frente ao ensiná-la nas escolas, além da lacuna que existe entre os conteúdos ministrados e a vivências dos estudantes, o que tem resultado, na maioria das vezes, uma aversão dos alunos aos temas e conteúdos relacionados com a disciplina. (CLEMENT, 2013; ANDRADE; SCARPAT; BUFFON, 2018;).

Feitosa e Menezes (2015) elucidam que os estudantes acreditam que a física não contribui de forma alguma para a sua formação profissional e cidadã, reforçando e até propagando a ideia de que é difícil aprender Física. Tais pressupostos estão inteiramente ligados às aulas voltadas extremamente aos conteúdos e fórmulas matemáticas.

Assim, têm surgido grupos de pesquisadores em diversas localidades do mundo que visam compreender, estudar e propor modelos de ensino que não direcione a formação somente dos estudantes para atender à necessidade das universidades e profissionalização, mas sim um ensino que atenda a todos, potencializando a soluções de problemas do seu âmbito quer seja social, pessoal e profissional - "Educar para Vida" (ZABALA, 2008).

Neste sentido, o método Ensino de Ciências por Investigação (EnCI) oferta, por meio de suas estruturas, elementos - proposta de problema, levantamento de hipótese, elaboração do plano de trabalho /planejamento, resolução do problema, discussão e análise - que favorecem a aprendizagem, além de promover a Alfabetização Científica. Induz os estudantes a reflexão frente às soluções e formulação de problemas, tomadas de decisões, formulação de hipótese, teste, análise, argumentação e interação coletiva, bem como a reformulação e construção do conhecimento (CARDOSO, 2017; SASSERON, 2015; CARVALHO et al., 2013).

Assim, Brito e Fireman (2016, p. 125) diante de seus estudos apontam o ensino por investigação como "uma metodologia de ensino que visa aproximar o aluno do 'fazer ciência' dos verdadeiros cientistas, por meio da resolução de problemas reais com espaço e tempo para questionamentos, testes de hipóteses, trocas de informações e sistematizações de ideias” corroborando para o entendimento quanto sua relevância e eficácia no processo de ensino aprendizagem dos discentes.

Desta forma, partindo deste contexto, o presente trabalho visa por meio do "Estado da Arte" averiguar as produções científicas, descrever como se tem dado a aplicação do método EnCI no ensino de Física e os temas já abordados nos últimos anos no Brasil, realizando um 
mapeamento sistematizado das produções, resultados e temáticas abordadas nesta área do conhecimento, assim como, a catalogação dos trabalhos encontrados em duas bases de dados.

A pesquisa denominada Estado da Arte é de extrema relevância, haja vista que possibilita constatar como tem se dado a produção sistemática científica de determinado assunto. No entanto, este tipo de pesquisa não é recente no país, visto que trabalhos intitulados como tal, estão presentes nos estudos de: Soares 1989 (Alfabetização no Brasil - o Estado do Conhecimento); Fiorentini 1994 (Rumos da pesquisa brasileira em educação Matemática: o caso da produção em cursos de pós-graduação); Reigota 2007 (O estado da arte da pesquisa em educação ambiental no Brasil); Bisol; Sangherlin e Valentini 2013 (Educação inclusiva: estudo de estado da arte das publicações científicas brasileiras em Educação e Psicologia); Medeiros e Dias 2015 (O estado da arte sobre a pesquisa em educação do campo na região nordeste, no período entre 1998 e 2015).

\section{Aspectos Metodológicos}

A presente pesquisa é caracterizada como qualitativa na perspectiva de Bogdan e Biklen (1994), na qual estabelecem cinco características necessárias dos quais estão presente neste estudo: I - origem direta dos dados, II - descrição dos dados, III - a relevância de todo o processo e não exclusivamente dos dados, IV - processo indutivo, V - respeitar cada individualidade no tratamento dos resultados.

Trata-se de um estudo bibliográfico, conforme elucida Severino (2007, p.122) "é aquele que se realiza a partir dos registros disponíveis, decorrente de pesquisas anteriores, em documentos tais como: livros, artigos, teses, etc." A principal fonte dos dados foram artigos na base de dados do Google acadêmico e SciELO, utilizando de 3 palavras chaves/descritores: 1Ensino de física, 2- Investigação no ensino de física e 3- EnCI, dispondo dos filtros de idiomas e período nas plataformas supracitadas, a fim de apurar, por meio das publicações recentes, como tem sido abordado a utilização do EnCI no ensino de Física.

Os critérios de seleção/inclusão foram: idioma em português, disposição de material completo e que retratasse a utilização de mecanismos do EnCI nas atividades ou de alguma forma correlacionasse o método com a disciplina de Física, assim como o recorte temporal 2013 -2018 .

Os trabalhos caracterizados como "Estado da Arte" derivam-se de estudos baseados apenas nos resumos, objetivando exclusivamente mapear dados de produções. Entretanto, analisar somente esse item, algumas vezes não é suficiente por não apresentar informações 
suficientes para uma apuração minuciosa. Por isso, analisaram-se os trabalhos na íntegra, pois, com análise detalhada do material, permite, além da seleção apurada, uma caracterização mais profunda (FERREIRA, 2002).

Na primeira busca realizada no dia 10 de dezembro de 2018, na base de dados do Google acadêmico utilizando o primeiro descritor, apresentou 1.090 .000 resultados, quando acrescentou o filtro dos últimos cinco anos (2013-2018) houve uma redução para 60.300. Aplicando outro filtro, apenas trabalhos em português, restaram 58.900. Como eram muitos arquivos para ser analisado, essa busca terminou no dia 13 do mesmo mês, selecionando 09 materiais que inicialmente pelo título parecia tratar da abordagem investigativa em Física, porém após análise minuciosa, restaram apenas 02 que atenderam aos critérios mencionados, bem como, estavam disposto em formato completo.

$\mathrm{Na}$ ocasião se iniciou a busca com o segundo descritor, utilizando os mesmos filtros subsequentes apresentaram 21.100 arquivos, sendo selecionados 14 trabalhos, destes apenas 07 corresponde à temática deste trabalho. Por fim, realizando a busca com o terceiro descritor, seguindo os mesmos filtros, apresentaram 945 trabalhos, dos quais se selecionou 04 que após análise seguindo os critérios de seleção já mencionados, restaram-se apenas 03.

Realizando a pesquisa na base de dados da SiELO no dia 18 de dezembro, utilizando os mesmos descritores com os filtros: pesquisa avançada, coleção - Brasil, periódicos - todos, idioma - português e ano de publicação - 2013 á 2018 , com o primeiro descritor, foram encontrados 202 arquivos, destes foi selecionado apenas 1, que tratava da temática analisada. Já no que se refere o segundo e terceiro descritores utilizados na outra base de dados, não apresentou nenhum resultado na busca.

\section{Resultados E DiscuSSÃo}

Os resultados obtidos neste estudo foram organizados e apresentados conforme o Quadro 1. Os trabalhos encontrados nessas bases de dados (Google Acadêmico e SiELO) estão descritos, ordenados cronologicamente pelos três descritores representados: $1^{\circ} \mathbf{D}$ - Ensino de Física, $\mathbf{2}^{\circ} \mathbf{D}$ - Investigação no Ensino de Física e $3^{\circ} \mathbf{D}$ - EnCI, seguido com os nomes dos autores, tipo de documento encontrado e o ano de publicação. 
Quadro 1 - Relação de arquivos das bases de dados analisadas

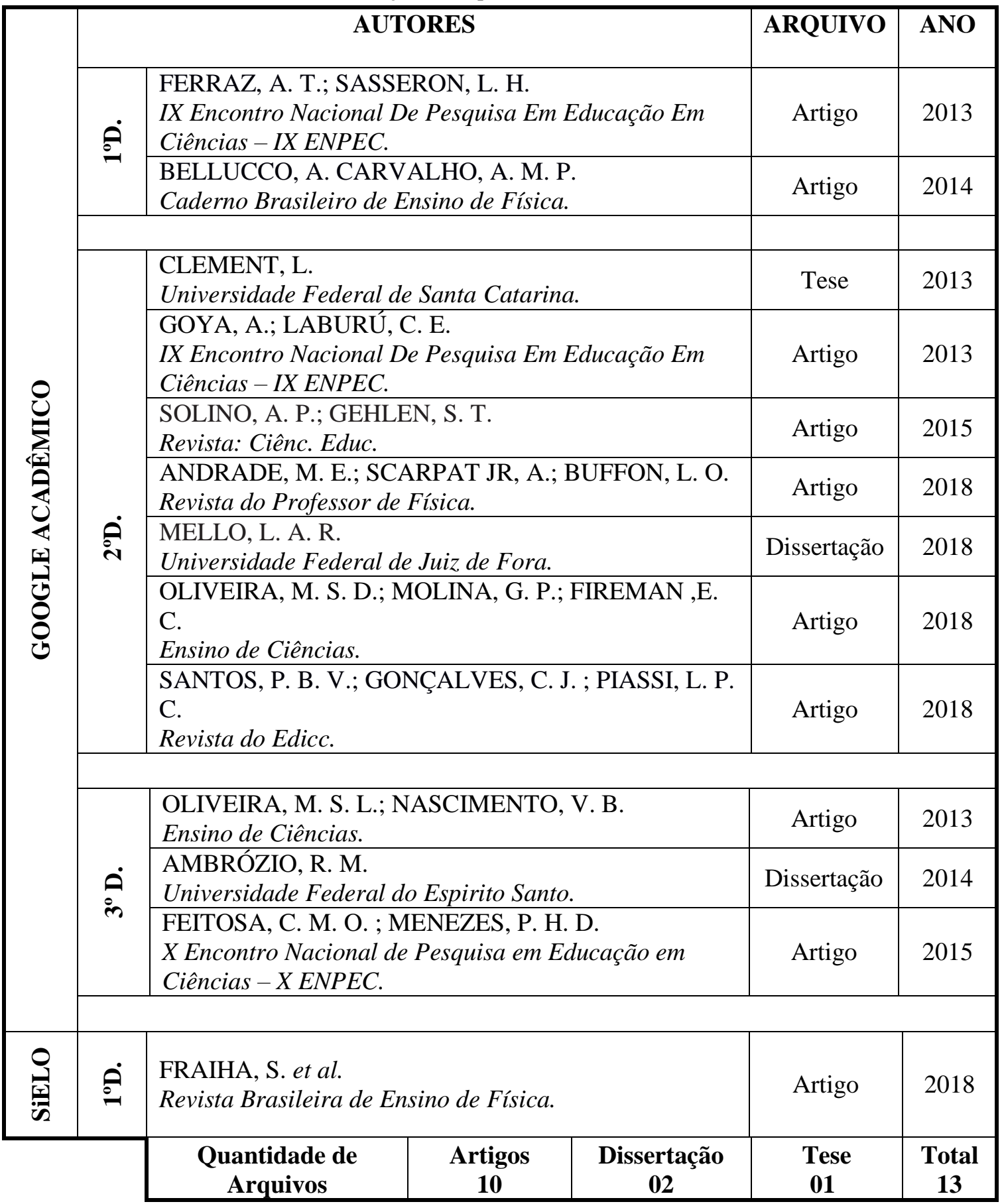

Fonte: Autores.

Posteriormente, são discutidos a partir dos Quadros (2, 3, 4 e 5) estruturados, primeiramente pelo local onde foi realizada a busca - banco de dados, os descritores um por vez de acordo com os achados, nome dos autores, título do trabalho e a principal temática da área da Física que se trabalhou utilizando a abordagem do ensino por investigação. 
Em seguida, realizou-se uma descrição, fazendo um breve comentário/análise de cada material, apontando: o local da publicação, percurso metodológico e os resultados que foram obtidos, assim como alguns pontos relevantes com a realização de tais atividades.

Com o primeiro descritor obtivemos dois arquivos (Quadro 2), na qual o primeiro foi apresentado no IX Encontro Nacional de Pesquisa em Educação em Ciências - IX ENPEC, 2013. O trabalho foi desenvolvido com uma turma do $3^{\circ}$ ano do ensino médio em uma escola pública do estado de São Paulo. Os autores dispuseram do que denominaram de Sequência do Ensino Investigativo, adaptada de Brockington (2005). Esta era composta por 12 aulas contendo atividades experimentais, discussões e reflexões abordando a temática.

Quadro 2 - Arquivos encontrados com o $1^{\circ}$ descritor na base de dado da Google Acadêmico

\begin{tabular}{|c|c|c|c|c|}
\hline \multirow{3}{*}{ 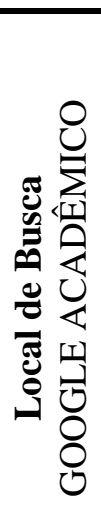 } & \multirow{3}{*}{ 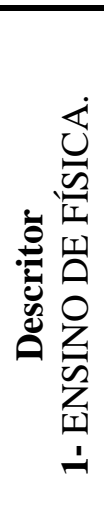 } & AUTOR & TÍTULO & TEMÁTICA \\
\hline & & $\begin{array}{l}\text { FERRAZ, A. T.; } \\
\text { SASSERON, L. } \\
\text { H. } \\
\text { (2013). }\end{array}$ & $\begin{array}{l}\text { Dualidade Argumentativa: Os } \\
\text { produtos da argumentação em } \\
\text { aulas investigativas. }\end{array}$ & $\begin{array}{l}\text { Dualidade de onda - } \\
\text { partícula da luz/ Física } \\
\text { Moderna e Contemporânea. }\end{array}$ \\
\hline & & $\begin{array}{l}\text { BELLUCCO, A. } \\
\text { CARVALHO, } \\
\text { A. M. P. } \\
\text { (2014). }\end{array}$ & $\begin{array}{l}\text { Uma proposta de sequência de } \\
\text { ensino investigativo sobre } \\
\text { quantidade de movimento, sua } \\
\text { conservação e as leis de } \\
\text { Newton. }\end{array}$ & $\begin{array}{l}\text { Quantidade de movimento e } \\
\text { sua conservação, e } \\
\text { fundamentado neste estudo, } \\
\text { introdução às atividades para } \\
\text { o ensino das leis de Newton. }\end{array}$ \\
\hline
\end{tabular}

Fonte: Autores.

Neste sentido, Ferraz e Sasseron (2013) refere mediante as observações, que foram perceptíveis à participação efetiva dos estudantes na construção de argumentos coletivos durante a realização dos experimentos. Logo, verificaram que pelo intermédio das atividades investigava diversas são as interações que resultam no aprendizado referente aos conceitos científicos.

No segundo trabalho, Bellucco e Carvalho (2014) publicaram no Caderno Brasileiro de Ensino de Física uma proposta de atividade para ser trabalhada com os estudantes do Ensino Médio, utilizando Sequências de Ensino Investigativas ou SEI's, proposta por Carvalho (2011; 2013). Esta retrata a realização de uma aula prática, permeando análise, reflexão e discussão.

Neste trabalho, os autores desenvolveram as atividades da seguinte forma: "Começamos com uma problematização que visa à construção da noção de quantidade de movimento e sua conservação e, em seguida, introduzimos atividades que estimulam a reflexão sobre as três leis de Newton ..." (BELLUCCO; CARVALHO, 2014, p. 41). 
Em seguida trabalhou com 4 sequência de atividades 1- Transferindo movimento: o problema do pêndulo de Newton; 2 - O que é quantidade de movimento afinal? O problema das colisões; 3 - Problemas abertos; 4 - Conservando os movimentos: as leis de Newton; 4.1 Perdidos no Espaço - A primeira lei de Newton; 4.2 - O que provoca um movimento? Variando a quantidade de movimento e a segunda lei de Newton; 4.3 - Interagindo e reagindo: a terceira lei de Newton; 5 - Avaliando. Os mesmos acreditam que essa SEI propicia o aparecimento de situações argumentativas para abordar um tema que consideram pouco explorado no ensino médio.

Quadro 3 - Arquivos encontrados com o $2^{\circ}$ descritor na base de dado da Google Acadêmico

\begin{tabular}{|c|c|c|c|c|}
\hline \multirow{5}{*}{ 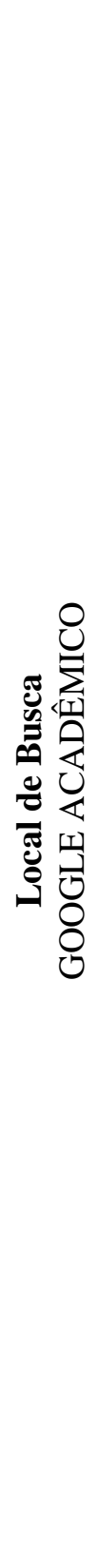 } & \multirow{5}{*}{ 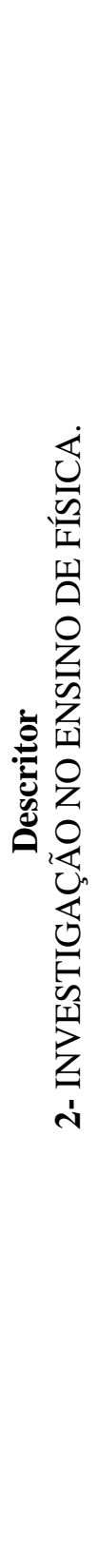 } & AUTOR & TÍTULO & TEMÁTICA \\
\hline & & $\begin{array}{l}\text { CLEMENT, L. } \\
\text { (2013). }\end{array}$ & $\begin{array}{l}\text { Autodeterminação e ensino } \\
\text { por investigação: } \\
\text { Construindo elementos para } \\
\text { promoção da } \\
\text { autonomia em aulas de } \\
\text { física. }\end{array}$ & $\begin{array}{l}\text { "Consumo" e custo da } \\
\text { energia elétrica; Circuito } \\
\text { elétrico; Lei de Ohm; } \\
\text { Resistores Código de cores } \\
\text { (determinação da resistência } \\
\text { elétrica); Consumo de } \\
\text { energia elétrica; Associação } \\
\text { de resistores; Gerador de } \\
\text { energia elétrica; Campo } \\
\text { magnético; Linhas de campo } \\
\text { magnético; Campo } \\
\text { magnético de um condutor } \\
\text { retilíneo; Lei de Biot Savart } \\
\text { e Ampère; Indução } \\
\text { Eletromagnética (Lei de } \\
\text { Faraday e Lei de Lenz); } \\
\text { Princípios de geração de } \\
\text { energia elétrica; Noções de } \\
\text { transmissão e distribuição } \\
\text { de energia elétrica. }\end{array}$ \\
\hline & & $\begin{array}{l}\text { GOYA, A.; } \\
\text { LABURÚ, C. E. } \\
\text { (2013). }\end{array}$ & $\begin{array}{l}\text { Uma estratégia de } \\
\text { investigação multimodal } \\
\text { para } \\
\text { física. }\end{array}$ & $\begin{array}{l}\text { Introdução a Física; } \\
\text { Mecânica Clássica } \\
\text { Newtoniana. }\end{array}$ \\
\hline & & $\begin{array}{l}\text { SOLINO, A. P.; } \\
\text { GEHLEN, S. T. } \\
\quad(2015) \text {. }\end{array}$ & $\begin{array}{l}\text { O papel da problematização } \\
\text { freireana em aulas de } \\
\text { ciências/física: articulações } \\
\text { entre a abordagem temática } \\
\text { freireana e o ensino de } \\
\text { ciências por investigação }\end{array}$ & $\begin{array}{l}\text { Flutuação, Massa; Volume } \\
\text { e Densidade; Pressão } \\
\text { Hidrostática. }\end{array}$ \\
\hline & & $\begin{array}{l}\text { ANDRADE, M. } \\
\text { E.; SCARPAT } \\
\text { JR, A.; BUFFON, } \\
\text { L. O. } \\
\text { (2018). }\end{array}$ & $\begin{array}{l}\text { O Uso de um software de } \\
\text { simulações para a } \\
\text { aprendizagem de circuitos } \\
\text { elétricos simples: uma } \\
\text { abordagem a partir do } \\
\text { ensino por investigação. }\end{array}$ & Circuitos elétricos simples. \\
\hline
\end{tabular}




\begin{tabular}{|c|c|c|c|c|}
\hline & & $\begin{array}{l}\text { MELLO, L. A. R. } \\
\text { (2018). }\end{array}$ & $\begin{array}{l}\text { Proposta de atividades de } \\
\text { ensino por investigação em } \\
\text { laboratório de indução } \\
\text { eletromagnética. }\end{array}$ & $\begin{array}{l}\text { Eletromagnetismo; A Força } \\
\text { Magnética; As Leis de Biot- } \\
\text { Savart e Ampère; A Lei da } \\
\text { Indução de Faraday. }\end{array}$ \\
\hline & & $\begin{array}{l}\text { OLIVEIRA, M. S. } \\
\text { D.; MOLINA, G. } \\
\text { P.; FIREMAN ,E. } \\
\text { C. } \\
\text { (2018). }\end{array}$ & $\begin{array}{l}\text { Contribuições das } \\
\text { sequências de ensino por } \\
\text { investigação para a } \\
\text { alfabetização científica no } \\
\text { estágio em ensino de Física. }\end{array}$ & Ensino de Física. \\
\hline & & $\begin{array}{c}\text { SANTOS, P. B. } \\
\text { V.; } \\
\text { GONÇALVES, } \\
\text { C. J. ; PIASSI, L. } \\
\text { P. C. } \\
\text { (2018). }\end{array}$ & $\begin{array}{l}\text { Experimentos de } \\
\text { astronomia com materiais } \\
\text { de baixo custo: } \\
\text { Ensino por investigação em } \\
\text { espaços não formais através } \\
\text { do projeto banca da ciência. }\end{array}$ & $\begin{array}{l}\text { Astronomia: Sistema Solar } \\
\text { em Escala de tamanho; } \\
\text { Estações do Ano (Solstício e } \\
\text { Equinóci); Sistema Sol- } \\
\text { Terra-Lua; Caixa das Fases } \\
\text { da Lua. }\end{array}$ \\
\hline
\end{tabular}

Fonte: Autores.

O primeiro trabalho apresentado no Quadro 3, trata-se de uma tese apresentada à Universidade Federal de Santa Catarina, no programa de Pós-Graduação em Educação Científica e Tecnológica. O trabalho foi realizado em uma escola pública, com a participação de 25 alunos de duas turmas do $3^{\circ}$ ano do Ensino Médio. Além de entrevista com professor das turmas, as atividades foram organizadas em 28 aulas de 45 minutos cada.

As atividades didáticas foram elaboradas baseadas em situações problemas com o regente da disciplina e posteriormente intervenção didático-pedagógica com atividades práticas. O autor da pesquisa (CLEMENT, 2013), verificou, diante as evidências significativas, de que é possível tal abordagem (EnCI) intervir pedagogicamente para que os estudantes atuem com protagonismo no processo de sua aprendizagem.

No trabalho desenvolvido por Goya e Laburú (2013), foi realizado com um grupo de acadêmicos do curso de Licenciatura em Química, na disciplina de Física de uma Universidade Pública do estado do Paraná.

Esta fora organizada em 7 momentos, entre aulas teóricas e de laboratório, na qual utilizou-se a estratégia investigativa multimodal, proposta anteriormente por Laburú em 2003, porém com nova denominação "Comunicação dos Resultados através de Multimodos e Múltiplas Representações". No trabalho, foi desenvolvido por ações maleáveis, seguindo a sequência “... I) Fenômeno; II) Problema; III) Hipóteses; IV) Plano de Trabalho; V) Análise; VI) Conclusão; VII) Comunicação dos Resultados através de Multimodos e Múltiplas Representações".

Foram avaliadas com observações do início ao final do semestre, as intervenções interações além da aplicação do questionário (Force Concept Interventory - FCI) composto por 
30 questões contendo cinco alternativas onde apenas uma condiz com conceito científico da temática trabalhada e o da escala de Likert ao termino que demarca duas variáveis, uma a orientação á meta de realização e a outra se aprendem estratégia pessoal de estudo.

Ao término pode constatar que os graduandos iniciam o semestre com muita dificuldade com $23,0 \%$ de acertos com relação à concepção newtoniana porém termina com $47,0 \%$ em média não alcançaram o pensamento newtoniano $60,0 \%$ o que pode ser perduradas do déficit durante o ensino médio. Também se conseguiu realizar a união entre a estratégia de investigação multimodal com algumas características da metodologia de investigação dispondo dos multimodos e múltiplas representações.

Dos 22 graduandos que fizeram parte do trabalho apenas 15 alcançaram a última etapa devida à desistência do curso, a maioria afirmou que as atividades de investigação, por envolver a prática do laboratório, levaram-nos a achar interessante, motivacional e a influir positivamente na compreensão dos conteúdos. Vários destacaram que a atividade prática exigiu muito trabalho, um ou outro afirmou que é mais complexa do que a teoria, e alguns afirmaram que não conseguiram aproveitar por falta de costume e preparação.

Solino e Gehlen (2015) realizaram o trabalho com uma turma do $5^{\circ}$ ano do ensino fundamental de uma escola municipal do estado de xxxx, com elaboração e desenvolvimento de 10 aulas, na qual três destas, envolveram atividades experimentais investigativas, baseada no EnCI.

A realização dessas atividades ocorreu no período de maio a junho de 2012, organizadas em 4 fases: escolha da temática/ conteúdos; elaboração do planejamento, desenvolvimento das ações em aula e análise da implantação.

Desta forma foi selecionado um problema de contexto social, ao qual se trata da poluição das águas de uma cachoeira que banha grande parte do município de Itabuna/BA . Neste, se abordou conceitos importantes da Química, Física; Biologia e Educação Ambiental. Nas atividades experimentais investigativas se buscou a resolutividade para tais problemáticas: Flutua ou Afunda? Proposto anteriormente no trabalho de Schiel e Orlandi em 2009, o problema do Barquinho e da Pressão publicado por Carvalho et al. em 1998.

Os dados deste se obtiveram a partir de observações, gravações em áudio de fala de alunos e produções escritas dos estudantes no decorrer das aulas assim como o diário do professor ao qual se avaliou pela análise textual discursiva.

Diante disso, os autores constataram que a problematização freireana, baseada em problemas que envolvam o contexto social, contribuiu para a estruturação de problemas nas 
atividades do EnCI nas disciplinas de Ciências/Física, além de propiciar aos estudantes a reflexão sobre situações problemáticas de sua realidade, e concomitante o favorecimento para exercerem uma postura investigativa diante dos problemas práticos que envolvam a ciência.

No quarto trabalho de Andrade; Scarpat Jr e Buffon (2018) retratam atividades realizadas no Instituto Federal do Espirito Santo, Campus Cariacica, com uma turma do ensino médio, para este utilizou-se do Software simulador elétrico EveryCircuit e o método Predizer, Observar e Explicar (POE) .

Desta forma, as atividades computacionais possuíam de três a quatro circuitos que deveriam ser analisados com base em uma determinada problemática específica de cada uma. Na primeira etapa (predizer), apresenta-se a proposta problematizadora que está relacionada ao funcionamento do circuito e os grupos de estudantes apresentam as hipóteses e tentam justificála. Na segunda etapa (observar), eles constroem no simulador o circuito e verificam o seu funcionamento relacionando-o ao problema da primeira etapa. Na terceira etapa (explicar), os aprendizes apresentaram explicações ao acontecimento averiguando se coincidiram com a hipótese feita inicialmente, devendo revisar os argumentos anteriores. Na quarta "Calculando" a partir dos dados das correntes e tensões obtidos nos enunciados dos circuitos a determinação de outros valores elétricos de grandezas.

Assim, a aplicação destas atividades segundo os autores do trabalho promoveram de forma significativa a participação e envolvimento dos estudantes com o objeto de estudo, mostrando também evidências de apropriação dos conceitos relacionados ao tema.

O quinto trabalho do Quadro 3, Melo (2018) também utilizou do método POE, com turmas do terceiro ano do ensino médio, a fim de apresentar aos educadores das escolas da rede pública e particular, alternativas para a fabricação de equipamentos para o laboratório de indução eletromagnética de custo reduzido e com qualidade comparável aos equipamentos disponíveis no mercado, além de apresentar uma metodologia para aproveitar esse material. Foram realizados quatro experimentos, além de propor experimentos que podem utilizar esses equipamentos, com uma abordagem investigativa, sendo eles: 1) Construção de uma Minibobina de Tesla, 2) uma bobina com quatro mil espiras ligada a diodos LED, 3) um tubo de Foucault e 4) uma bobina chata.

Desse modo, ao aplicar o produto nas turmas das escolas, o autor verificou que os resultados foram positivos, com aumento do interesse desses estudantes, melhora na relação com o docente e facilitação para formalizar os conceitos nas aulas teóricas. 
Oliveira; Molina e Fireman (2018) realizaram a pesquisa durante o $6^{\circ}$ semestre do estágio supervisionado com os acadêmicos do curso de Licenciatura em Física de uma universidade pública do estado de Alagoas, com a implementação das Sequencias de Ensino por Investigação (SEI), com a finalidade de exercitar a alfabetização científica em formação inicial.

Assim, refere-se como uma proposta analítica de um caso, onde foram analisados os diálogos no fórum online desenvolvidos e construídos no ambiente virtual Moodle, juntamente com o grupo focal, ao término da experiência. No que se refere ao percurso analítico teve como referencia a Análise Sociológica do Discurso. Os autores constaram que o contínuo exercício do desenvolvimento e da implementação das SEI contribui significativamente para a alfabetização científica dos futuros professores; que tal abordagem possibilitou o contato direto do estudante com a linguagem da ciência, passando de um conhecimento instintivo a um conhecimento científico.

O trabalho de Santos; Gonçalves e Piassi (2018) analisaram os Experimentos confeccionados no projeto Banca da Ciência com materiais de baixo custo e de fácil acesso. Este projeto incide na realização de apresentações dos experimentos, visando à exploração do aspecto da ludicidade.

Este atua em diversos ambientes - formais ou não, e as práticas podem contemplar qualquer que seja área do conhecimento Física, Biologia, Química, Astronomia, Geologia, ao quais são expostos em uma bancada, na qual o público tende a interagir com os mesmos. Neste, foram analisados os seguintes experimentos: Sistema Solar em Escala de tamanho; Estações do Ano (Solstício e Equinócio); Sistema Sol-Terra-Lua e a Caixa das Fases da Lua.

Assim sendo, os autores observaram que os temas que abordam escala de tamanho dos planetas, Planeta Anão, eclipses, estações do ano, sistema Terra, Lua e Sol tornam-se simplificadas ao serem compreendidos com os experimentos realizados. A utilização do ensino por investigação tem se mostrado eficaz para despertar o interesse sobre o assunto, pois através dele, incentivamos o público a buscar proposições/hipóteses para resolver os problemas apresentados.

O Quadro 4, apresenta os arquivos obtidos na base de dados do Google Acadêmico com o terceiro descritor (EnCI), apresentando o nome dos autores, o título do trabalho e a área da física trabalhada com a abordagem investigativa. 
Quadro 4 - Arquivos encontrados com o $3^{\circ}$ descritor na base de dado da Google Acadêmico

\begin{tabular}{|c|c|c|c|c|}
\hline \multirow{4}{*}{ 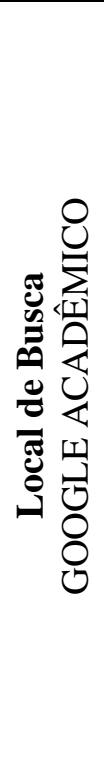 } & \multirow{4}{*}{ 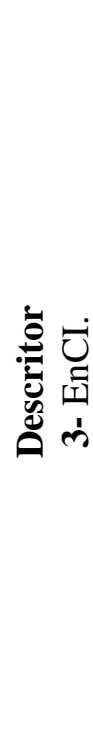 } & AUTOR & TÍTULO & TEMÁTICA \\
\hline & & $\begin{array}{l}\text { OLIVEIRA, M. } \\
\text { S. L.; } \\
\text { NASCIMENTO, } \\
\text { V. B. } \\
\text { (2013). }\end{array}$ & $\begin{array}{l}\text { Ensino de ciências por } \\
\text { investigação: uma sequência } \\
\text { didática para o ensino de } \\
\text { eletromagnetismo. }\end{array}$ & $\begin{array}{l}\text { Eletromagnético e lei de } \\
\text { indução de Faraday. }\end{array}$ \\
\hline & & $\begin{array}{c}\text { AMBRÓZIO, R. } \\
\text { M. } \\
\text { (2014). }\end{array}$ & $\begin{array}{l}\text { Uma intervenção Educacional } \\
\text { com Enfoque no Ensino por } \\
\text { Investigação: Abordando as } \\
\text { Temáticas Termodinâmica e } \\
\text { Óptica. }\end{array}$ & Termodinâmica e Óptica. \\
\hline & & $\begin{array}{l}\text { FEITOSA, C. } \\
\text { M. O. ; } \\
\text { MENEZES, P. } \\
\text { H. D. } \\
\text { (2015). }\end{array}$ & $\begin{array}{l}\text { A eletricidade e seus riscos: } \\
\text { uma perspectiva reflexiva para } \\
\text { o ensino de física }\end{array}$ & Eletricidade e seus riscos. \\
\hline
\end{tabular}

Fonte: Autores.

O primeiro trabalho do Quadro 4, refere ao de Oliveira e Nascimento (2013) onde realizou uma proposta de atividade com uma do $3^{\circ}$ ano do Ensino Médio. Priorizando compreender os conceitos teóricos do EnCI, a fim da elaboração de sequência didática, contendo características do método, sendo primordial para a efetivação do ensino do eletromagnetismo. O conteúdo abordado foi dividido em 12 aulas.

Tratando-se de uma proposta diferenciada para o ensino de eletromagnetismo, ao qual visa a ultrapassar dificuldades presentes no ensino de Ciências/Física, como o desinteresse dos estudantes em estudar conteúdos relacionados à temática e o descompromisso com os estudos relacionados a essa área do conhecimento. A proposta foi elaborada segundo os autores a partir dos trabalhos publicados por pesquisadores que abordam as atividades investigativas.

No trabalho de Ambrózio (2014) é relatada uma sequência de três atividades participativas experimentais com simulação computacional, realizada com estudantes do $2^{\circ}$ ano do ensino médio de uma escola estadual de Vitória/ES. Iniciou-se com aulas expositivas com apresentação de experimentos em algumas delas e, por fim, a utilização do Applet Java, pois os fenômenos abordados apresentam aspectos microscópicos visíveis neste software. Para a utilização deste fora criado um tutorial e entregue para os membros dos cinco grupos de estudantes, para dar suporte, bem como instruções de componentes que eram indispensáveis para elaboração do plano de investigação.

Durante a execução das atividades, a autora observou que o ensino pautado em atividades investigativas promoveu maior envolvimento dos estudantes com o objeto de estudo. 
No primeiro contato com atividades dessa natureza, os estudantes reagiram em sua maioria com alguma resistência, uma vez que não estamos lidando apenas com a apresentação de novos saberes, onde eles devem exercer o protagonismo de sua produção do conhecimento. Visto que, essa proposta de ensino permite aos estudantes a desenvoltura de habilidades como autonomia, criticidade, aprender a dialogar diante do seu posicionamento frente à temática, a refletir, discutir e ouvir, assim como aprender com os próprios erros.

Feitosa e Menezes (2015) abordam uma atividade realizada com estudantes do $1^{\circ}$ ano do ensino médio de uma escola pública do interior de Minas Gerais. O projeto foi desenvolvido em três etapas, a saber: I- leitura compartilhada de um encarte informativo da companhia de distribuição de eletricidade; II- Investigação em casa dos riscos da eletricidade, fotografá-los para analisarem em conjunto na aula e a divisão em grupo; e III- apresentação em slides e confecção de cartazes.

Segundo os autores, tais ações tiveram como intuito em responder os questionamentos "Quais os riscos da utilização da eletricidade, envolvendo choques elétricos e curtos circuitos? De que forma o aprendizado da Física pode contribuir para atenuar esses riscos?". Os resultados mostraram que o envolvimento dos estudantes com a atividade proposta, pode facilitar a sistematização de conceitos futuros e potencializam o processo de ensino aprendizagem, bem como os induzem ao desenvolvimento da pesquisa e correlação com os conceitos científicos.

O Quadro 5, apresenta o único trabalho disposto nesta base de dados da SciELO, encontrado com o primeiro descritor. É importante ressaltar que com os demais descritores não evidenciaram trabalhos divulgados no período que se refere o estudo.

Quadro 5 - Arquivos encontrados com o $1^{\circ}$ descritor na base de dado da SciELO

\begin{tabular}{|c|c|c|c|c|}
\hline & & AUTOR & TÍTULO & TEMÁTICA \\
\hline 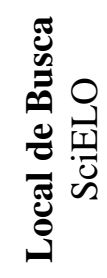 & 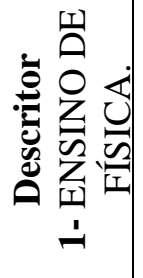 & $\begin{array}{c}\text { FRAIHA, S. et } \\
a l . \\
(2018) .\end{array}$ & $\begin{array}{l}\text { Atividades investigativas e o } \\
\text { desenvolvimento de } \\
\text { habilidades e competências: } \\
\text { um relato de experiência no } \\
\text { curso de Física da } \\
\text { Universidade Federal do Pará. }\end{array}$ & $\begin{array}{l}\text { Ensino de Física. (Leis de } \\
\text { Newton, Leis de } \\
\text { Conservação na Mecânica } \\
\text { Clássica, Leis básicas da } \\
\text { Termodinâmica e } \\
\text { Eletromagnetismo). }\end{array}$ \\
\hline
\end{tabular}

Fonte: Autores.

A didática do segmento da atividade proposta por Fraiha et al. (2018) consistiu em formar equipes para desenvolvimento de problemas abertos, utilizando como referência para as temáticas os abordados no International Young Physicist Tournment (IYPT- torneio internacional de Física voltado para o ensino médio) disposto pelo professor da disciplina. 
Desses, selecionou-se: Canhão Eletromagnético (IYPT 2010); Pêndulo Magnético (IYPT 2015); Geladeira de Potes (IYPT 2014); Coeficiente de difusão (IYPT 2014); Invente você mesmo (IYPT 2017); Músculo Artificial (IYPT 2015); Usina de Velas (IYPT 2014); Pêndulo Defasado (IYPT 2016); Ouvindo a Luz (IYPT 2013) e apenas um apontado no trabalho de conclusão de curso, A dança dos surdos (UFPA 2017).

Após a divisão iniciou-se com a fase inicial do problema, onde retrataram em sala os principais conceitos envolvidos com as temáticas acima pelo professor e posteriormente a apresentação de seminário pelos grupos. Em seguida, no desenvolvimento reuniram individualmente por grupo com o professor e começaram a elaboração dos 'aparatos experimentais'. Ao final do semestre, todos os grupos realizaram reflexão do primeiro seminário, apresentação de outro com discussão dos conceitos relacionados com o aparato experimental, além da confecção de rascunho do trabalho em formato de artigo.

Com isso, os autores observaram maiores respeito à liberdade criativa e ao ritmo de aprendizado de cada estudante no que se refere ao aprendizado dos conceitos de Física relevantes, bem como ao desenvolvimento de competências relacionadas à capacidade de resolver problemas de cunho científico e do seu cotidiano.

\section{CONSIDERAÇÕES FINAIS}

A partir deste levantamento bibliográfico, foi perceptível a ausência de produção de trabalhos desse cunho na área da Física, nas bases de dados pesquisadas, no período estipulado. Como visto, das duas grandes principais bases de dados utilizadas para pesquisas científicas acadêmicas soma-se uma média de $13 \%$ de produção encontrada. O que permite aos pesquisadores da área a oportunidade de publicar trabalhos com temas inéditos. Além disso, percebe-se que a maioria da produção nesta delimitação de tempo se deu no evento Encontro Nacional de Pesquisa em Educação em Ciências -ENPEC, que acontece bienalmente no país.

Assim, diante dos pressupostos apresentados no decorrer deste trabalho, mediante as análises dos materiais divulgados, é notória a unanimidade dos autores quanto à eficiência da utilização do método investigativo no processo de ensino, visto que este propicia a autonomia da produção do conhecimento individual e coletiva, assim como a aproximação do sujeito, a partir de sua realidade e saberes, com o saber científico - Alfabetização Científica. 


\section{REFERÊNCIAS}

AMBRÓZIO, Rosa Maria. Uma intervenção Educacional com Enfoque no Ensino por Investigação: Abordando as Temáticas Termodinâmica e Óptica. 2014. 88 f. Dissertação (Mestre em Ensino de Física) - Universidade Federal do Espirito Santo, Vitória - ES, 2014.

ANDRADE, Marcelo Esteves de; SCARPAT JR, Alfeu; BUFFON, Luiz Otávio. O Uso de um software de simulações para a aprendizagem de circuitos elétricos simples: uma abordagem a partir do ensino por investigação. Revista do Professor de Física, vol. 2, n. 2, p.59-72, 2018.

BELLUCCO, Alex. CARVALHO, Anna Maria Pessoa de. Uma proposta de sequência de ensino investigativo sobre quantidade de movimento, sua conservação e as leis de Newton. Caderno Brasileiro de Ensino de Física, v. 31, n. 1, p. 30-59, 2014.

BOGDAN, Robert C.; BIKLEN, Sari Knopp. Investigação Qualitativa em Educação: uma introdução à teoria e aos métodos. Porto - Portugal. Porto: Editora, 1994. 333 p.

BRITO, Liliane Oliveira de; FIREMAN, Elton Casado. Ensino de ciências por investigação: uma estratégia pedagógica para promoção da alfabetização científica nos primeiros anos do ensino fundamental. Ensaio Pesquisa em Educação e Ciências, v. 18(1), p. 123-146, 2016.

CARDOSO, Milena Jansen Cutrim. Identificação e descrição de elementos de ensino de ciências por investigação em aulas de professores em formação inicial. 2017. 170 f. Dissertação (Mestrado em Ciências - Área de Concentração em Biologia) Universidade de São Paulo. Faculdade de Educação Instituto de Física, Instituto de Química e Instituto de Biociência, São Paulo, 2017.

CARVALHO, Anna Maria Pessoa de; OLIVEIRA, Carla Marques Alvarenga de; SCARPA, Daniela Lopes; SASSERON, Lúcia Helena; SEDANO, Luciana; SILVA, Maíra Batistoni e; CAPECCHI, Maria Candida Varone de Moraes; ABIB, Maria Lucia Vital dos Santos; BRICCIA, Viviane. Ensino de Ciências por Investigação: condições para implementação em sala de aula. São Paulo: Cengage Learning, 2013. 164 p.

CLEMENT, Luiz. Autodeterminação e ensino por investigação: Construindo elementos para promoção da autonomia em aulas de física. 2013. $334 \mathrm{f}$. Tese. (Doutor em Educação Cientifica e Tecnológica). - Universidade Federal de Santa Catarina, Florianópolis - SC, 2013.

FEITOSA, Cristiane Maria de Oliveira; MENEZES, Paulo Henrique Dias. A eletricidade e seus riscos: uma perspectiva reflexiva para o ensino de física. In: $X$ ENCONTRO NACIONAL DE PESQUISA EM EDUCAÇÃO EM CIÊNCIAS - X ENPEC, 2015, Água de Lindóia - SP. Ensino e aprendizagem de conceitos científicos, 2015. 01-08 p.

FERRAZ, Arthur Tadeu; SASSERON, Lúcia Helena. Dualidade Argumentativa: Os produtos da argumentação em aulas investigativas. In: ATAS DO IX ENCONTRO NACIONAL DE PESQUISA EM EDUCAÇÃO EM CIÊNCIAS - IX ENPEC, 2013, Águas de Lindóia, SP, 2013. 01-08 p. 
FERREIRA, Norma Sandra de Almeida. As pesquisas denominadas "estado da arte".

Educação \& Sociedade, ano XXIII, 79, 257-272, 2002. Disponível em: < http://www.scielo.br/pdf/es/v23n79/10857.pdf > Acessado dia 19 de dezembro de 2018.

FRAIHA, Simone; PASCHOAL JR. Waldomiro; PEREZ, Silvana; TABOSA, Clara. E. S.; ALVES, João Paulo da Silva; SILVA, Charles Rocha. Atividades investigativas e o desenvolvimento de habilidades e competências: um relato de experiência no curso de Física da Universidade Federal do Pará. Revista Brasileira de Ensino de Física, vol. 40, n. 4, e 4401- 4407, 2018.

GOYA, Alcides; LABURÚ, Carlos Eduardo. Uma estratégia de investigação multimodal para física. In: ATAS DO IX ENCONTRO NACIONAL DE PESQUISA EM EDUCAÇÃO EM CIÊNCIAS - IX ENPEC, 2013, Águas de Lindóia, SP, 2013. 01-08 p.

MELLO, Luiz Arthur Rodrigues de. Proposta de atividades de ensino por investigação em laboratório de indução eletromagnética. 2018. 116 f. Dissertação (Mestre em Ensino de Física) - Universidade Federal de Juiz de Fora, Juiz de Fora - MG, 2018.

OLIVEIRA, Maria do Socôrro Dias de Oliveira; MOLINA, Gonzalo Peña; FIREMAN, Elton Casado. Contribuições das sequências de ensino por investigação para a alfabetização científica no estágio em ensino de física. Ensino de Ciências, v.13, n.4, p. 266-296, 2018.

OLIVEIRA, Marcel da Silva Lessa de; NASCIMENTO, Viviane Briccia do. Ensino de ciências por investigação: uma sequência didática para o ensino de eletromagnetismo. In: ATAS DO IX ENCONTRO NACIONAL DE PESQUISA EM EDUCAÇÃO EM CIÊNCIAS - IX ENPEC, 2013, Águas de Lindóia, SP, 2013. 01-08 p.

SANTOS, Paulo Borges Viríssimo dos; GONÇALVES, Carolina Jürgensen; PIASSI, Luis Paulo de Carvalho. Experimentos de astronomia com materiais de baixo custo: Ensino por investigação em espaços não formais através do projeto banca da ciência. In: $5^{\circ}$ ENCONTRO DE DIVULGAÇÃO DE CIÊNCIA E CULTURA - Revista do Edicc, v. 5, n. 1, p.221-229, 2018.

SASSERON, Lúcia Helena. Alfabetização Científica, Ensino por Investigação e Argumentação: Relações Entre Ciências da Natureza e Escola. Rev. Ensaio, Belo Horizonte, v.17 n. especial, p. 49-67, 2015.

SEVERINO, Antônio Joaquim. Metodologia do trabalho científico. 23. ed. rev. e atual. São Paulo: Cortez, 2007. 320p.

SOLINO, Ana Paula; GEHLEN, Simoni Tormölhen. O papel da problematização freireana em aulas de ciências/física: articulações entre a abordagem temática freireana e o ensino de ciências por investigação. Ciênc. Educ.,v. 21, n. 4, p. 911-930, 2015.

ZABALA, Antoni. Enfoque Globalizador e Pensamento Complexo: uma proposta para o currículo escolar. Porto Alegre: Artmed Editora, 2002. 248p.

Recebido em: 06 de fevereiro de 2020.

Aprovado em: 16 de abril de 2020. 